\title{
Ética profesional y su concepción responsable para la investigación científica
}

Professional ethics and its responsible conception for scientific research

Recibido: mayo 22 de 2016 | Revisado: agosto 12 de 2016 | Aceptado: setiembre 26 de 2016

\author{
Nadiezhda Coasaca Sotomayor ${ }^{1}$ \\ George Argota Pérez ${ }^{2}$ \\ Luis Celi SaAvedra ${ }^{3}$ \\ Rosalvina Campos PÉrez \\ Sheda MÉndez AnCCA ${ }^{5}$
}

1 Centro de Investigaciones avanzadas y Formación Superior en eduación, Salud y Medio Ambiente "AMTAWI" coasacasotomayor@gmail.com

2 Centro de Investigaciones avanzadas y Formación Superior en eduación, Salud y Medio Ambiente "AMTAWI" george.argota@g.mail.com

3 Universidad de San Martín de Porres lcelis@usmp.pe

4 Universidad de San Martín de Porres rosalvina17@gmail.com

5 Universidad Nacional de Moquegua. Moquegua, Perú

shedamendez@gmail.com

\section{Resumen}

En la actualidad, la ética profesional constituye el erario conductual en la humanidad, donde no siempre se expresa de forma consciente para su contribución a las investigaciones científicas como aporte al desarrollo social. El objetivo de la presente investigación fue comentar sobre la ética profesional y su concepción responsable para la investigación científica. Para ello, no solo se tuvo en cuenta el significado desde la dimensión antigua, sino además contemporánea. Se indicó la necesidad de reconocer los valores en profesionales, así como los principios y normas que rigen cualquier código de ética profesional. Se concluyó que la ética es una dimensión reflexiva inherente a la formación $y$ al quehacer profesional; ella le permite a la persona no solo comprender el mundo en el que le corresponde actuar, sino también que le ofrece criterios orientadores para entenderse con sus semejantes en acciones cotidianas y comunes.

Palabras clave: ética profesional, investigación científica, normas, principios, responsabilidad, valores

\begin{abstract}
Currently, professional ethics represent mankind's behavior exchequer, which it is not always expressed consciously for its contribution to scientific research as well as to social development. The goal of this research was to comment on professional ethics and its responsible conception for scientific investigation. In order to achieve this, not only did we consider the meaning from the old dimension, but also the contemporary one. We emphasize the need to recognize values in professionals, as well as the principles and rules governing any code of professional ethics. It was concluded that ethics is an reflective dimension inherent to both training and professional work; it allows the person not only to understand the world in which it must operate, but also offers guiding criteria for understanding their peers in everyday situations.
\end{abstract}

Keywords: professional ethics, scientific research, standards, principles, responsibility, values 


\section{Introducción}

El término "ética" procede del vocablo griego antiguo ethos que significaba en un principio: estancia, vivienda común. Posteriormente, adquirió otros significados: hábitos, temperamento, carácter, modo de pensar. La ética es la ciencia que trata sobre la moral (moralidad). Como filosofía de la moral se pregunta lo siguiente: ¿por qué se consideran válidos unos comportamientos y otros no? Compara las pautas morales que presentan diferentes personas o sociedades, busca su fundamento y legitimación, investiga aquello que es específico al comportamiento moral, enuncia principios generales y universales inspiradores de toda conducta. Tan antiguo como la misma humanidad, es el interés por regular mediante normas o códigos, las acciones concretas de los seres humanos. En todas las comunidades, pueblos, sociedades y culturas existen prescripciones para un buen comportamiento, las mejores prácticas y prohibiciones que definen su ética y moral.

En la esfera estrictamente profesional, la ética proporciona un marco de trabajo para dirigir las funciones esenciales de los especialistas, establecer políticas y desarrollar estrategias para los servicios o bienes que producen (Guséinov, Járchev, Sogomónov, Titarenko \& Barkshtanovski, 1986) y en el contexto mundial, la tendencia dominante en la formación profesional es la propuesta de una formación integral que comprenda las capacidades y competencias para acceder al mundo del trabajo, pero también los valores y las actitudes que moldean la personalidad del sujeto y que contribuyen al logro de un desempeño comprometido y eficaz de su profesión, así como a un ejercicio responsable de la ciudadanía.

Los pilares de la formación integral son dos: la formación en competencias profesionales, y la formación ética que requieren complementarse como dos dimensiones que se articulan para preparar al profesional del nuevo milenio. En este marco, la ética profesional se ha situado como un componente dinámico y sustantivo de la formación integral porque asegura una práctica responsable y eficaz al normar el buen uso de las capacidades profesionales, lo que resulta fundamental para enfrentar y resolver los complejos problemas de la sociedad contemporánea.

La ética profesional puede cumplir esta función porque es la indagación sistemática acerca del modo de mejorar, cualitativamente, y elevar el grado de humanización de la vida social e individual, mediante el ejercicio de la profesión. Entendida como el correcto desempeńo de la propia actividad en el contexto social en el que se desarrolla, donde se ofrecerían las pautas concretas de actuación y valores que habrían de ser potenciados. En el ejercicio de cada profesión, es donde el hombre encuentra los medios para contribuir a elevar el grado de humanización de la vida personal y social (Fernández \& Hortal, 1994; como se citó en Hirsch, 2004).

Para Ibarra (2005), la ética profesional es la expresión de una conciencia moral que posibilita el logro del bienestar social y contribuye a la realización plena del profesionista. Esto es así porque esta ética recupera y antepone a cualquier otro interés, el sentido social de la profesión que consiste en proporcionar a la sociedad los bienes y servicios que requiere para satisfacer sus necesidades. Asimismo, la ética profesional como toma de conciencia moral, permite que el profesionista asuma el compromiso y la responsabilidad de contribuir a través de su práctica profesional a mejorar y elevar las condiciones de vida de una sociedad. En el ejercicio de esa responsabilidad, el profesionista encuentra el camino para su realización porque las aportaciones que hace a la sociedad implican el desarrollo pleno de sus capacidades profesionales, la búsqueda y el logro de la excelencia 
y de la calidad en la prestación de bienes y servicios. En este ámbito, la ética contribuye a mejorar la condición profesional y humana de la persona.

Es por ello, que la ética va más allá del conjunto de prohibiciones y deberes que se adquieren al formar parte de una comunidad profesional (código deontológico) porque no se reduce a reglamentar la conducta, sino que impulsa y guía la realización de acciones que redunden en beneficio de la sociedad y del profesionista. Este carácter práctico que tiene la ética, en el quehacer profesional, permite reconocer que no forma parte del ámbito de las especulaciones filosóficas, sino que como ética aplicada genera efectos y acciones positivas. En este marco, los profesionistas que egresan de las instituciones de educación superior, al adquirir un conjunto de conocimientos especializados y de competencias profesionales, no solo logran obtener el estatus y el poder de expertos especialistas en un área de conocimientos o campo de acción, sino también contraen la responsabilidad moral de hacer un buen uso de esas competencias profesionales porque la aplicación de esos conocimientos especializados inciden, de manera directa o indirecta, en las condiciones de vida y en el bienestar de la población. La ética recupera la dimensión moral de las competencias profesionales al vincular su aplicación y uso con la responsabilidad profesional (Salas, 2012).

Para Hortal (2002), la responsabilidad profesional involucra las siguientes dimensiones: (a) implica responder a las necesidades y problemáticas de la sociedad, proporcionando los bienes intrínsecos de la profesión como son salud, educación, vivienda, justicia, etc., para lo cual es necesario que el profesionista anteponga estos a los bienes extrínsecos que se refieren a la obtención de recompensas económicas, de poder, prestigio y de estatus. (b) en el marco de la prestación de los bienes intrínsecos, la responsabilidad del profesionista se expresa también en realizar bien el servicio o la tarea y función que le ha sido encomendada.

Esto significa hacer uso de la competencia especializada con el nivel de excelencia y de calidad que se esperan del profesionista en tanto que experto o especialista, porque constituye la manera en que aporta un beneficio a la sociedad. Estos aspectos que encierra la responsabilidad muestran que la ética profesional fortalece y enriquece la formación universitaria, ya que la formación, en la responsabilidad profesional, no se limita a proporcionar principios y valores morales, sino que también involucra la preparación rigurosa y de calidad en las competencias profesionales para que el futuro profesionista pueda asumir esa responsabilidad hacia las demandas y necesidades sociales con el nivel de capacitación adquirido.

El principio de responsabilidad de la ética profesional contribuye también a la realización práctica profesional eficaz puesto que el compromiso de hacer bien las funciones $y / o$ prestar un servicio desarrollando al máximo las capacidades profesionales deviene en el logro de los productos y/o resultados que la sociedad o el cliente esperaban obtener con la intervención de un profesionista. La ética es también necesaria en la formación profesional porque constituye un soporte del desarrollo de la personalidad y del carácter del sujeto que, actualmente, se consideran componentes estructurales de las capacidades profesionales.

En la sociedad contemporánea, la noción de calificación profesional como conjunto de conocimientos y habilidades asociadas a un puesto de trabajo y a la realización de tareas específicas está caducando, y en su lugar, aparece una noción de competencias profesionales que incluyen no solo conocimientos y destrezas, sino también el comportamiento, las actitudes, los valores y todas aquellas cua- 
lidades personales que le permitan al profesionista actuar con capacidad de autonomía, de juicio y de responsabilidad profesional y social. Este conjunto de cualidades, que dependen en gran medida de la personalidad y del carácter del profesionista, han adquirido el rango de calificaciones profesionales y son altamente valoradas en el mundo del trabajo, ya que tienen la misma importancia que el dominio de conocimientos y habilidades.

En este sentido, la ética coadyuva a moldear la personalidad y el carácter del profesionista al dotarlo de principios y valores morales que norman su comportamiento y que posibilitan un proceder ético en su quehacer profesional. Asimismo, le proporciona el criterio y el juicio ético que también contribuyen a fortalecer sus capacidades profesionales, puesto que tienen un papel activo en la toma de decisiones (Días, 2006; Ribes, 2006; Ruiz, 2009).

Hirsch (2003) señala las características que distinguen a la ética profesional para complementar y enriquecer las capacidades profesionales. Tiene un doble cometido: utiliza en la actividad profesional criterios y principios de la ética básica y aporta criterios o principios específicos. Su objetivo es proporcionar los elementos que se requieren para estructurar un proceder ético habitual en el mundo del ejercicio profesional. Se alimenta de dos fuentes: ética de las profesiones y criterios profesionales que aportan las disciplinas científicas. No le incumbe propiamente solucionar casos concretos, sino diseñar los valores, principios y procedimientos que los afectados deben tomar en cuenta en los diversos casos.

Se trata de un marco reflexivo para la toma de decisiones en el que se traduce que la ética profesional refuerza la capacidad de respuesta del profesionista al proporcionarle principios, procedimientos y valores éticos que contribuyen a mejorar la elaboración de criterios y juicios propios, así como la elec- ción y toma de decisiones, puesto que constituyen un referente necesario para discernir, valorar, ponderar y optar por alternativas de respuesta o de solución a los problemas propios de su profesión. El criterio y el juicio ético como componentes de este marco reflexivo, contribuyen a orientar la práctica profesional hacia la búsqueda y formulación de respuestas que sean posibles y viables de tener impacto en las condiciones de vida de la sociedad.

La formación profesional no debe perder de vista que este marco reflexivo es expresión de una racionalidad que dota de sentido el hacer profesional, sin el cual el ejercicio profesional puede devenir en una práctica estrecha y limitada que se oriente al desempeño en sí mismo y se centre solo en asegurar las acciones y ejecuciones. La ética profesional fortalece las capacidades transformadoras del profesionista, pero esto requiere de la integración de conocimientos, habilidades y destrezas, así como de actitudes y valores éticos (Ibarra, 2005; Zabala, \& Arnau, 2007).

Es importante considerar que desde hace años se libra una dura batalla en el campo de la ética de las profesiones. El punto de partida, o mejor el telón de fondo, lo constituye la imagen tradicional o clásica de las profesiones. Para saber lo que esto significa, nada mejor que acudir a la clásica descripción de Parsons (1947). Los profesionales han sido vistos durante siglos, o mejor milenios, como seres investidos de un rol superior que les concedía un estatus de excepción. Esto tenía sus consecuencias morales, dado que les situaba para utilizar la conocida frase de Nietzsche "más allá del bien y del mal».

Esto ha cambiado drásticamente, como han dejado en claro los estudios sociológicos aparecidos durante los años sesenta y setenta, donde se pueden citar, los realizados por Freidson (1970). Es en esos tiempos cuando los roles de excepción comenzaron poco 
a poco a sufrir una crítica implacable. Las diferencias clásicas entre oficios y profesiones comienzan a reducirse, hasta el punto de que hoy, ya no es posible seguir hablando de una "moralidad especial" de las profesiones a diferencia de los oficios. Hay, desde luego peculiaridades relacionadas con el tipo de actividad que se realiza. Pero esto no afecta solo a las profesiones clásicas, sino a todos y cada uno de los roles ocupacionales.

Como es conocido, los politólogos del Renacimiento y posteriores han fundamentado el Estado, en un contrato social, efectuado entre los miembros de una comunidad humana. El estado civil sería consecuencia de ese acuerdo de voluntades. La agrupación anterior no podría ser llamada civil, sino solo natural. Pero esto, argumentan los más clásicos, no deja de ser extrańo. Se dice que el contrato lo hacen los miembros de una comunidad humana. Pero si se trata de una comunidad, tiene ya una cierta estructura, no solo biológica, sino también social y política. Lo cual supone tanto como afirmar que hay un estado civil anterior al Estado que fundamenta el llamado contrato social o expresado en otros términos. El Estado es una comunidad natural antes que un contrato social. Esta fue, de hecho la opinión clásica, como lo demuestra la República de Platón y la Política de Aristóteles. Esta última comienza con las siguientes palabras: «Toda Estado (pólis) es una comunidad (koinonía) y toda comunidad está constituida en vista de algún bien» (Aristóteles, 1252).

El recurso de Platón y Aristóteles es interesante, pues permite explicar muchas cosas. La tesis de ambos es que todas las cosas de la naturaleza, incluidas las estructuras sociales tienen un fin interno. Esto es lo que los clásicos llamaron su télos o fin natural. Toda estructura tiene como finalidad el cumplir una función que constituye por eso mismo la razón de ser o la esencia de esa estructura. El télos nos da siempre la razón de ser de las estructuras de la naturaleza y por tanto, su bien. Lo dice expresamente Aristóteles, en las primeras líneas de la Ética a Nicómaco: "Todo arte y toda investigación y del mismo modo toda acción y elección, parecen tender hacia algún bien; por esto se ha dicho con razón que el bien es aquello a que todas las cosas tienden»

Si esto es así, entonces resulta claro que para definir una profesión es necesario identificar su télos o finalidad interna, es decir, aquella función a la que naturalmente se dirige. En el caso de la medicina, parece claro que ese fin es la promoción de la salud y de la vida. Hay muchos textos de Aristóteles en este sentido. Platón sostiene: «Por causa de la enfermedad que es un mal, es amigo [el enfermo] de la medicina y la medicina es un bien. $Y$ es por la salud por lo que la medicina ha adquirido esta amistad [del enfermo], pues la medicina es un bien».

Finalmente, la característica esencial que distingue a la ética profesional es que rescata y pone al día el sentido y la razón de ser de las profesiones. Para Cortina (2000), la profesión va más allá de una ocupación que permite obtener ingresos y estatus social, puesto que en realidad es una práctica social que adquiere su verdadero sentido y significado en el bien o servicio que proporciona a la sociedad. Hortal (2002), coincide en este punto en el que fundamenta la dimensión ética de la profesión, al señalar que el profesionista, al adquirir los conocimientos y las habilidades que lo distinguen como tal, también adquiere el compromiso y la responsabilidad de prestar bien y de manera eficiente el servicio o bien que le compete y por el cual la sociedad lo acepta y reconoce como profesionista. En esta misma línea, Fernández y Alonso (1994), distinguen la esencia del quehacer profesional al reconocer que su verdadero valor radica en la forma cómo "contribuye a elevar el grado de humanización de la vida personal y social". 
Podría decirse que, en el caso de las profesiones, la capacidad humanizadora de la ética profesional se traduce en proporcionar a la sociedad los bienes y servicios que contribuyan al logro de una vida digna y plena. Por ello, se considera que esta ética es la expresión de una racionalidad que dota de sentido el quehacer profesional, porque no pierde de vista los bienes intrínsecos que le dan razón de ser a la profesión. Esto se refiere a que la ética profesional busca que el médico anteponga la salud y el bienestar del paciente; que el profesor se preocupe y ocupe de la formación de sus educandos; que el juez se esfuerce por la impartición de la justicia y que cada profesión proporcione los bienes y servicios propios de su profesión que justifiquen y legitimen su existencia como grupo profesional en la sociedad moderna. De esta forma, la ética profesional contribuye a que el ejercicio profesional no se transforme en una práctica estrecha y limitada que se oriente al desempeño en sí mismo y se centre solo en asegurar las acciones y ejecuciones sin considerar la responsabilidad que involucra su actuación como parte sustantiva de su profesionalidad (Granja, 2004). En este marco, puede preguntarse ¿̇cuáles son los rasgos principales de la ética profesional y cómo complementa a los códigos deontológicos?

En principio, es preciso señalar que los códigos deontológicos son, generalmente, resultado de los colegios o las asociaciones de profesionistas que se agrupan como colectivos para realizar acciones conjuntas, debatir y definir o también en ocasiones, reglamentar aspectos sustantivos de la profesión, así como ejercer el control y el monopolio del ejercicio profesional. Estas agrupaciones se dotan a sí mismas de un conjunto de normas y deberes éticos que se proponen regular la conducta y el ejercicio profesional que representan. De acuerdo con Hortal (2002), la ética profesional, como ética filosófica, ofrece a estos códigos deontológicos un horizonte amplio en donde pueden encontrar principios y criterios para reflexionar lógicamente sobre los aspectos éticos de cada profesión en particular. La importancia de estos principios es que son justamente los que le permiten a la ética profesional recuperar el sentido del quehacer profesional. Estos principios son: el de beneficencia, el de autonomía y el de justicia.

El principio de beneficencia establece que el profesional nunca debe actuar en perjuicio del cliente, siempre debe buscar el beneficio o bienestar de quien solicita sus servicios. Este principio se fundamenta en el hecho de que la ética profesional es una ética de bienes y virtudes. En relación con los bienes, siempre se pregunta ¿qué tipo de bienes busca como finalidad cada profesión? es decir, se plantea qué satisfacción o beneficio puede proporcionar una profesión a la sociedad. Los bienes específicos de cada profesión se definen en el horizonte del bienestar que puedan aportar a la sociedad a través del ejercicio profesional. De tal modo, que el principio de beneficencia solo es la expresión de la razón de ser de la actividad profesional.

El principio de autonomía comprende tanto la capacidad que tiene el profesionista en tanto que experto en tomar decisiones respecto al problema propio de su ámbito profesional como también recuperar lo que considere conveniente el cliente, así como su opinión y decisiones. Este principio busca que norme el equilibrio y la equidad entre el profesionista y el cliente para evitar conflictos éticos y de intereses (Hirsch, 2003). El principio de justicia recupera el sentido social de la profesión, es decir, plantea que cada profesión tiene el compromiso de buscar, en los diferentes contextos y situaciones profesionales, el bien común que es la expresión de una vida digna donde prevalece la justicia y la equidad.

Las características y los principios de la ética profesional muestran que la formación 
ética en la universidad no debe reducirse a los códigos deontológicos de cada profesión ya que, si bien resulta importante para el futuro profesionista conocer los deberes y obligaciones que el gremio profesional ha establecido, la ética profesional además de centrarse en el comportamiento ético, se propone formarlo en un horizonte ético mucho más amplio, en el sentido social y en la razón de ser de la profesión.

Es común asociar la ética a normas, deberes y obligaciones morales que se imponen para regir el comportamiento. De acuerdo con esta visión, el comportamiento ético se limita al apego de los dictados establecidos por la moral. Desde el punto de vista de Camacho (1995), esta forma de comprender y ejercer la ética encierra las siguientes limitaciones:

a. Como conjunto de deberes y obligaciones, la ética queda reducida al automatismo normativo donde no cabe espacio alguno para el ejercicio de la libertad y de la responsabilidad.

b. La ética como conjunto de prohibiciones deviene en una ética negativa, en tanto que se presenta como una coerción, que encubre su verdadera esencia que consiste en ser una ética de valores, esto es, una ética afirmativa que enriquece a la condición humana.

Según esta perspectiva, si bien la ética profesional comprende principios y criterios, la adhesión a los mismos conlleva la opción libre y decidida por parte del profesionista, lo cual constituye un ejercicio de libertad e independencia. La ética profesional es afirmativa porque detrás de sus principios se encuentran los valores profesionales, por lo que le plantea al profesional, la posibilidad de ejercer su libertad y autonomía en la elección y adhesión a los valores profesionales que le son propios o inherentes. En este marco, el quehacer profesional ético va más allá del acatamiento de reglas de obligación o prohibición, más bien se define como una actuación en función de valores que finalmente definen su modo en cada contexto como pueden ser las organizaciones laborales, un espacio educativo representado por las aulas o el entorno ambiental que entre todos definen a la sociedad (Lecaros, 2013; Treviño, Butterfield \& McCabe, 1998; Vargas, 2004).

Los valores son un filtro que posibilita que la ética profesional no se imponga como una coerción externa del colectivo profesional, puesto que involucran el reconocimiento y la identificación del profesionista con esos valores que dotan de significado el ejercicio profesional (Alvarado, 2004; Hernández, 2010).

Es conveniente considerar sobre los valores profesionales que comprenden y promueven la ética, en tanto que ideales, representan algún modelo o prototipo de profesión que se pretenden alcanzar; y por ello dotan de significado al ejercicio profesional. Son altamente valorados y tienen impacto en el comportamiento y en el quehacer profesional por las cualidades humanizadoras que encierran. En este punto, cabe señalar los aspectos que comprenden los valores del compromiso y de la responsabilidad profesional. En relación con el compromiso, Hortal (2002) precisa que, en principio, todo profesional que adquiere los conocimientos y las competencias profesionales también adquiere el compromiso de prestar a la sociedad el servicio o bien que le compete y por el cual está formado y preparado profesionalmente.

El valor del compromiso profesional resulta fundamental para que el profesionista adquiera conciencia de que sus capacidades profesionales solo adquieren sentido en la prestación del servicio o bien que es propio de su profesión y por las cuales la sociedad lo acepta y reconoce como profesionista (Uvalle, 2014). 
En segundo término, este valor es esencial para que el profesionista anteponga los bienes intrínsecos de la profesión por encima de los bienes extrínsecos como son el dinero, el poder, el prestigio, el estatus, etc., los cuales se adquieren también a través del ejercicio profesional. Este compromiso ético es inherente a la profesión, ya que el profesional que adquiere esta condición y que forma parte de un colectivo o comunidad profesional también se adhiere al convenio tácito de buscar la realización del fin o bien intrínseco que es propio de la profesión. Si bien el ejercicio profesional es un medio de sustento, es preciso señalar que el compromiso ético con la profesión determina que el médico tenga como meta o fin el bienestar y la salud del paciente, que el abogado busque el logro de la justicia para con su cliente y que cada una de las profesiones realice su actividad profesional considerando como eje el fin de su profesión. El valor del compromiso profesional contribuye, de esta forma, a la realización de un ejercicio profesional ético que engloba dos componentes: la excelencia en la competencia profesional y el proceder ético, el cual no se restringe a un comportamiento "bueno" apegado a las normas y hábitos convencionales de la profesión, sino que apunta a las acciones positivas que puede realizar el profesionista a través de su quehacer para contribuir al logro del bienestar de la sociedad. No debe perderse de vista que, en la ética profesional, el compromiso ético se enmarca en la aportación que pueda hacer el profesionista para elevar el grado de humanización de la vida social, donde resulta de extraordinaria importancia toda gestión a nivel universitario para que los aportes sociales sean tangibles (Uvalle, 2014; Zambrano, 2007).

De acuerdo con Hortal (2002), en principio, el valor de la responsabilidad involucra la realización del ejercicio profesional con el nivel de excelencia y de calidad que distinguen al profesionista como tal. Esto signifi- ca que el profesionista que ha adquirido las competencias y capacidades profesionales, también asume la responsabilidad de desarrollar al máximo y de manera óptima esas competencias en la prestación del servicio o bien que le compete. En este nivel, la responsabilidad ética resulta fundamental para proporcionar bien y de manera eficiente los servicios profesionales, porque la aplicación rigurosa de los conocimientos y habilidades profesionales aseguran la obtención de logros o buenos resultados del ejercicio profesional.

La responsabilidad profesional asegura la actualización y capacitación permanente del profesionista puesto que para asumir este valor requiere mantenerse al día en cuanto a los conocimientos y las competencias que comprende su ejercicio profesional (Vanegas, 1994).

Gracias al valor de la responsabilidad profesional, la forma como el profesionista contribuye a mejorar las condiciones de vida de la sociedad es mediante la realización competente de su quehacer profesional. Vinculado con lo anterior, el mismo Hortal (2002) señala que la responsabilidad profesional comprende también el compromiso que tienen las profesiones de contribuir al bienestar individual y social. Aquí es importante señalar que la responsabilidad profesional no se reduce a realizar bien y de manera eficiente el ejercicio profesional, también significa el ejercicio profesional ético que implica el buen uso de las competencias profesionales porque la aplicación de esos conocimientos y habilidades profesionales inciden, de manera directa e indirecta, en las condiciones de vida de la sociedad y en el bienestar de la población. En este marco, el valor de la responsabilidad permite al profesionista tomar conciencia de las repercusiones que tiene su ejercicio profesional y asumir el sentido social de la profesión como una práctica cuyo fin último es contribuir al bienestar del individuo y de la sociedad. 
El valor de la responsabilidad también enriquece las competencias profesionales ya que pone al día la capacidad de autonomía del profesionista para enfrentar los problemas y tomar decisiones, fortalece el criterio y el juicio propios y además constituye el soporte del comportamiento solidario con los más necesitados (Civila, 2011; De Febres, 2007).

\section{- Código de la ética profesional. Princi- pios y normas}

Un código de ética es un reglamento elaborado por determinada institución que puede estar referido a lineamientos marcos de cualquier entidad nacional o internacional. Independientemente de cuál sea el organismo o sector por el cual se elabora, todos tienen en común dar a conocer cuál es el rol que cada trabajador deberá desempeñar frente a la sociedad y hacerlo cumplir de forma justa.

Todo código de ética está estructurado por Principios éticos y Normas éticas. No es objetivo en este artículo, indicar o realizar una descripción detallada sobre los aspectos a tenerse en cuenta sobre determinado Código de Ética pero sí resaltar lo que es usual en todos ellos.

\section{a. Principios éticos}

Los principios son las señales que indican la conducción correcta del actuar y que deberán estar acordes con la moral referida a tal modo u otra forma que no es aplicada a determinada (s) situación (es) concreta (s), sino en todo espacio y momento dado que finalmente es discernida para cada caso en lo particular. Los principios éticos están referidos a la beneficencia, autonomía y equidad.

- Beneficencia: hacer el bien. Este principio indica el imperativo de hacer el bien a todos. Se pueden identificar tres niveles de obligatoriedad: nivel básico (debe hacer el bien al menos no causando mal. Se refiere a todo ser humano y con más razón a un profesional. Cuando alguien recurre a un profesional tiene el derecho a exigirle que por lo menos no debe ser perjudicado por su actuar. Nivel profesional (debe hacer el bien ayudando a solucionar determinadas necesidades humanas) El profesional responde a un requerimiento particular con los conocimientos que le ha dado la sociedad. Nivel universal (debe hacer el bien a toda la persona: Se refiere a la totalidad de la persona esto es su conciencia, su autonomía y su comunitariedad).

- Autonomía: es la capacidad del sujeto de gobernarse por una norma que él mismo acepta como tal sin coerción externa. Esta aptitud esencial del ser humano es la raíz del derecho a ser respetado en las decisiones que una persona toma sobre sí misma sin perjudicar a otros.

- Equidad: se refiere al principio general de justicia aplicado a las relaciones interpersonales. Asimismo, establece que partiendo de una sociedad no corrompida, compuesta por seres iguales, maduros y autónomos, estos integrantes estructurarían dicha sociedad sobre bases racionales estableciendo que los criterios o bienes primarios accesibles para todos estén compuestos por libertades básicas como conciencia y pensamiento, con libertad de movimiento, de elegir ocupación, poseer como base la igualdad de diversas oportunidades, tener posibilidad de ejercer tareas de responsabilidad de acuerdo con las capacidades 
de gobierno y autogobierno, así como también la posibilidad de poseer renta y riqueza, además de tenerse respeto a sí mismo como persona.

\section{b. Normas éticas}

Reglas que se deben seguir o las que se deban ajustar a las conductas, tareas y actividades. Las normas éticas establecen las acciones que permiten llegar hacia los valores éticos y fundamentalmente, son la confidencialidad, veracidad y fidelidad.

- Confidencialidad: todo lo que se observe u oyera, deberá quedar reservado por otra $u$ otras personas.

- Veracidad: no mentir como acto tácito de interrelación con las demás personas.

- Fidelidad: ser leal al saber y entendimiento.

Existen muchos adjetivos, que indistintamente, se relacionan con los principios y las normas donde en más de un código de ética se reflejan y entre ellos, se pueden mencionar los siguientes:

- Respeto por los derechos y la integri- dad de las personas

- Competencia

- Compromiso profesional y científico

- Integridad

- Independencia

- Responsabilidad social

- Confidencialidad

- Objetividad

- Aplicabilidad y límite de acción del código

- Respeto hacia y por los otros

- Interferencias personales en el ejercicio profesional

- Honestidad y sinceridad

- Secreto profesional

- Respeto a la libre elección

- Respeto por la autonomía

- Término de la relación profesional

\section{Conclusión}

Se concluyó que la ética es una dimensión reflexiva inherente a la formación y al quehacer profesional; ella le permite a la persona no solo comprender el mundo en el que le corresponde actuar, sino también que le ofrece criterios orientadores para entenderse con sus semejantes en acciones cotidianas y comunes. 


\section{Referencias}

Alvarado, A. (2004). La ética del ciudadano. Revista Aquichan, 4(4), 30-39. Recuperado de http://www.scielo.org.co/ pdf/aqui/v4n1/v4n1a05.pdf

Camacho, I. (1995). La ética y su proyección sobre algunos aspectos de la economía. En Universidad Deusto, La Etica en la Universidad: orientaciones básicas (pp. 39-56). Bilbao, España: Universidad Deusto.

Civila, A. (octubre, 2011). La responsabilidad y la corresponsabilidad como valor educativo. Trabajo presentado en el XII Congreso Internacional de Teoría de la Educación, Barcelona, España. Recuperado de http://www.cite2011. com/Comunicaciones/A+R/055.pdf

Cortina, A. (2000). Presentación, el sentido de las profesiones. En A. Cortina y J. Conill, 10 Palabras Clave en Ética de las Profesiones (pp. 13-28). Navarra, España: Verbo Divino.

De Febres, R. (enero/junio, 2007). Para crecer en un valor. Revista Educación en Valores, 1(7), 119-121. Recuperado de http://servicio.bc.uc.edu.ve/multidisciplinarias/educacion-en-valores/ v1n7/v1n72007-14.pdf

Díaz, A. (enero/marzo, 2006). El enfoque de competencias en la educación. ¿Una alternativa o un disfraz de cambio? Perfiles educativos, 28(111), 7-36.

Fernández, J. L. \& Hortal, A. (1994). Ética de las profesiones jurídicas. Madrid, España: Universidad Pontificia Comillas de Madrid.

Freidson, E. (1970). Profession of Medicine. A study of the sociology of applied knowledge. New York: Dodd, Mead and Company.
Granja, D. M. (2004). Kant: Conciencia reflexiva y proceso humanizador. Estudios, 71, 143-173.

Guséinov, A., Járchev, A., Sogomónov, Y., Titarenko, A. \& Bakshtanovski, V. (1986). Ética. Moscú: Editorial Progreso.

Hernández, S. M. (enero/abril, 2010). Educación y ética. Sociológica, 25(72), 215-227. Recuperado de http:// scielo.unam.mx/pdf/soc/v25n72/ v25n72a10.pdf

Hirsch, A. (2003). Elementos significativos de la ética profesional. Reencuentro, $38,8-15$.

Hirsch, A. (2003). Ética Profesional como Proyecto de Investigación. Teoría de la Educación, 15, 235-258.

Hirsch, A. (2004). Ética profesional. Algúns elementos para a súa comprensión. Revista Galega do Ensino, 43, 169-179.

Hortal, A. (2002). Ética General de las Profesiones. Bilbao, España: Desclée De Brouwer.

Ibarra, G. (2005). Ética y formación profesional integral. Reencuentro, 43. Recuperado de http://www.redalyc.org/ articulo.oa?id=34004303

Lecaros, J. A. (Noviembre, 2013). La ética medio ambiental: principios $y$ valores para una ciudadanía responsable en la sociedad global. Acta Bioethica, 19(2), 177-188. doi: http://dx.doi.org/10.4067/S1726569X2013000200002

Parsons, T. (1947). The professions and social structure 1939. In T. Parsons (Ed.). Essays in sociological theory (pp. 56-77). New York: Free Press. 
Ribes, E. (junio, 2006). Competencias conductuales: su pertinencia en la formación y práctica profesional del psicólogo. Revista Mexicana de Psicología, 23(1), 19-26.

Ruiz, G. (2009). El enfoque de la formación profesional en torno a la generación de competencia: ¡ejercicio impostergable o "lo que sucedió a un rey con los burladores que hicieron el paño"? Estudios pedagógicos, 35(1), 287-299.

Salas, R. S. (2012). Los procesos formativos, la competencia profesional y el desempeño laboral en el Sistema Nacional de Salud de Cuba. Revista Cubana de Educación Médica Superior, 26(2), 163-165. Recuperado de http://scielo. sld.cu/pdf/ems/v26n2/ems01212.pdf

Treviño, L. K., Butterfield, K. D., \& McCabe, D. L. (July, 1998). The ethical context in organizations: Influences on employee attitudes and behaviors. Business Ethics Quarterly, 8(4), 447-476. doi: http://dx.doi.org/10.2307/3857431
Uvalle, R. (mayo/agosto, 2014). La importancia de la ética en la formación de valor público. Estudios Políticos, 32, 59-81. Recuperado de http://www. scielo.org.mx/pdf/ep/n32/n32a4.pdf

Vanegas, G. (junio, 1994). Responsabilidad profesional. Revista Estomatología, 4(1), 33-36. Recuperado en http:// estomatologia.univalle.edu.co/index. $\mathrm{php} / \mathrm{estomatol} / \mathrm{article} / \mathrm{view} / 99$

Vargas, Z. R. (2004). Desarrollo moral, valores y ética; una investigación dentro del aula. Educación, 28(2), 91-104. Recuperado en http://www.redalyc. org/pdf/440/44028206.pdf

Zabala, A. \& Arnau, L. (2007). La enseñanza de las competencias. Aula de Innovación Educativa, 161, 40-46.

Zambrano, E. (noviembre, 2007). El valor de la ética para alcanzar la excelencia en la gerencia universitaria. Revista NEGOTIUM, 3(8), 30-63. Recuperado en http://www.revistanegotium. org.ve/pdf/8/Art2.pdf 